\title{
The AMMA field campaigns: accomplishments and lessons learned
}

\author{
Thierry Lebel, ${ }^{1}$ * Douglas J. Parker, ${ }^{2}$ Cyrille Flamant, ${ }^{3}$ Hartmut Höller, ${ }^{4}$ Jan Polcher, ${ }^{5}$ Jean-Luc Redelsperger, ${ }^{6}$ \\ Chris Thorncroft, ${ }^{7}$ Olivier Bock, ${ }^{8}$ Bernard Bourles, ${ }^{9}$ Sylvie Galle,' Béatrice Marticorena, ${ }^{10}$ Eric Mougin, ${ }^{\prime \prime}$ \\ Christophe Peugeot, ${ }^{12}$ Bernard Cappelaere, ${ }^{12}$ Luc Descroix,' Arona Diedhiou,' Amadou Gaye ${ }^{13}$ \\ and Jean-Philippe Lafore ${ }^{14}$ \\ I IRD/UJF-Grenoble I/CNRS/G-INP, LTHE UMR 5564, Grenoble, F-3804I, France \\ ${ }^{2}$ School of Earth and Environment, University of Leeds, Leeds, UK \\ ${ }^{3}$ LATMOS/IPSL/CNRS, Paris, France \\ ${ }^{4}$ Deutsches Zentrum für Luft- und Raumfahrt, Institut für Physik der Atmosphäre, Oberpfaffenhofen, Germany \\ ${ }^{5}$ LMD/IPSL/CNRS, Paris, France \\ ${ }^{6}$ CNRM/CNRS, Toulouse, France \\ 7 University at Albany, SUNY, Albany, NY, USA \\ ${ }^{8}$ IGN/LAREG, Paris, France \\ ${ }^{9}$ LEGOS/IRD, Toulouse, France \\ 10 LISA/CNRS, Créteil, France \\ " LMTG/CNRS, Toulouse, France \\ ${ }^{12}$ HSM/IRD, Montpellier, France \\ 13 LPA/UCAD, Dakar, Sénégal \\ ${ }^{14}$ CNRM/Météo-France, Toulouse, France
}

* Correspondence to:

Thierry Lebel,

IRD/UJF-Grenoble I/

CNRS/G-INP, LTHE UMR 5564,

Grenoble, F-3804I, France.

E-mail:

thierry.lebel@ujf-grenoble.fr

Received: 26 February 2010

Revised: 12 December 2010

Accepted: 12 December 2010

\begin{abstract}
The AMMA (African Monsoon Multidiscplinary Analysis) field programme aimed at documenting the West African Monsoon (WAM) climate system, in all its geophysical components. It also includes an important socio-economic component. Encompassing a wide range of spatial and time scales, AMMA is one of the most ambitious such programmes ever set up. While the key accomplishments of AMMA are summarised in this paper, a few lessons of broad interest are also drawn both as a tribute to the extraordinary efforts made by a community of several hundreds of people and as possible guidelines for ensuring a long lasting future to integrated climate and environmental studies in West Africa. Copyright (c) 2011 Royal Meteorological Society
\end{abstract}

Keywords: field campaigns; instrument deployment; long-term monitoring; capacity building; West Africa

\section{Introduction}

AMMA (African Monsoon Multidiscplinary Analysis) is an integrated research programme on the West African Monsoon (WAM) climate system, in all its geophysical components (Redelsperger et al., 2006). It also includes an important socio-economic component, making it a very ambitious project in terms of data to be collected in order to feed all of the underlying scientific investigations. By contrast to previous campaigns by meteorologists and/or hydrologists in West Africa (for instance GATE in 1973 or HAPEX-Sahel from 1991 to 1993), AMMA is thus gathering a much broader scientific community working over a much larger spectrum of scales. AMMA is much more than a collection of field campaigns, but field campaigns played a key role in the first phase of the programme that ended in 2009 and it is thus an appropriate time to reflect on the accomplishments and lessons learned from these activities.

\section{Summary of the AMMA field campaign}

The AMMA field deployment was unique, whether considering its 3-year intensive duration, the continental scales covered, or the harshness of the environment. Lebel et al. $(2009,2010)$ provide a relatively extensive description of the long-term monitoring setup, and of the Enhanced Observing Period (EOP) and Special Observing Period (SOP) setups, respectively.

It is important to appreciate that the AMMA field campaigns followed a scale-nested design, both in time and in space. The AMMA field programme has had to take account of the fact that the operational networks over West Africa are not documenting adequately all the variables of interest for the three scales targeted by AMMA to study the WAM, namely (1) the regional scale, controlling monsoon processes and interactions between the atmosphere, land and tropical Atlantic ocean; (2) the mesoscale, which is the scale of the typical rain-producing weather systems in the WAM, the characterisation of which is pivotal 

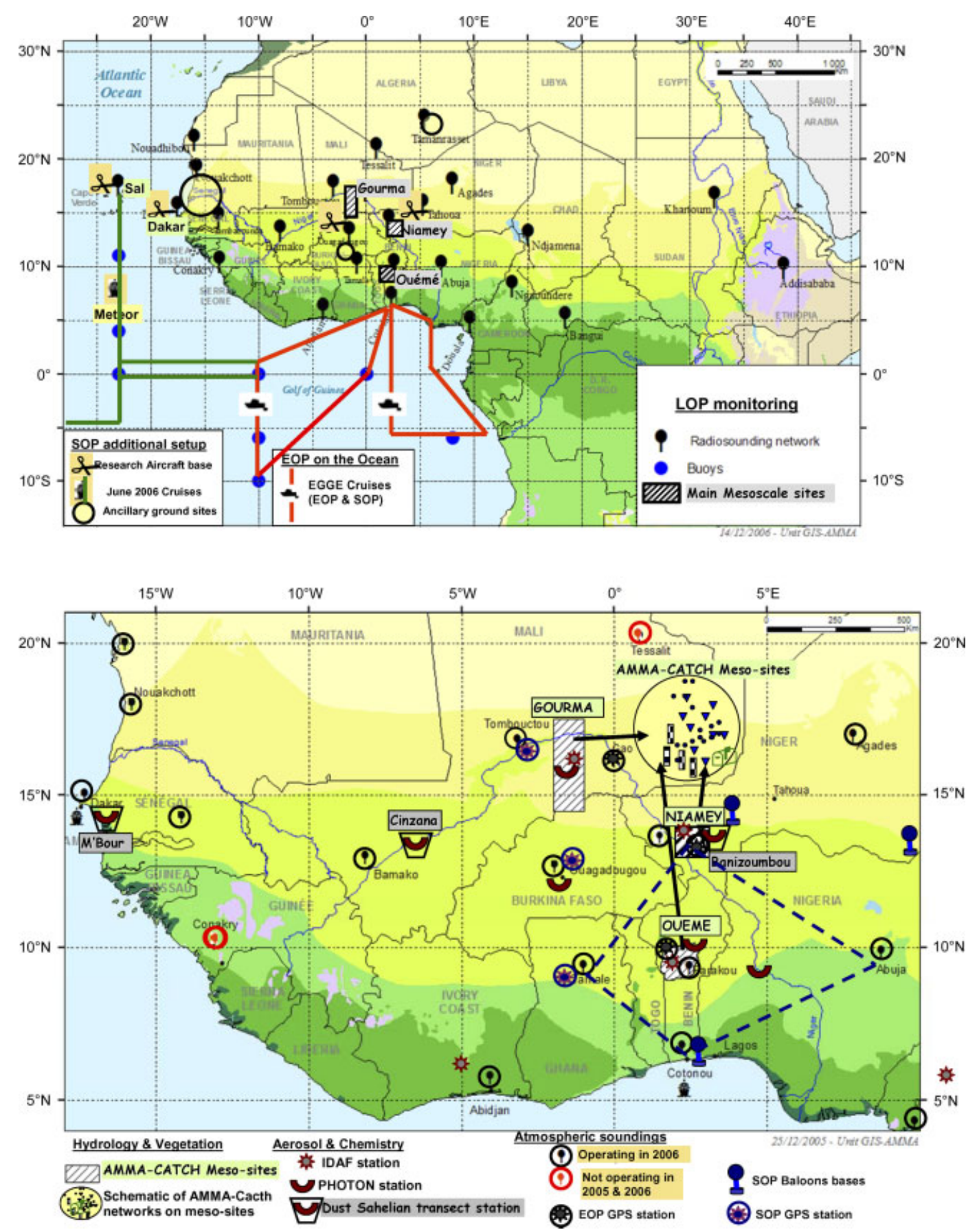

Figure I. The AMMA observing system at regional scale. The continent networks listed in Table I are covering the AMMA-CATCH mesoscale sites (hatched areas).

for hydrological, water resources and agricultural studies; (3) the sub-mesoscale which corresponds to heavily instrumented super-sites on which some key aerosol emission and hydrological processes, as well as their interaction with vegetation growth, are studied. Figure 1 provides a global view of AMMA's monitoring network at the regional scale, whose deployment started in 2002, with the long-term observations on the three hatched mesosites of Gourma in Mali, NiameyFakara in Niger and Ouémé catchment in Bénin.

The rainy season of West Africa displays a high interannual variability, with important consequences on the water cycle, crop production and climate-related pandemics and epidemics. In order to sample various types of rainy season (including early $v s$ late onset, early $v s$ late ending, more or less intense and frequent intraseasonal breaks), a long-term monitoring programme started in 2002, and lasted until at least 2010, with 26 instruments, ${ }^{1}$ corresponding to several

\footnotetext{
${ }^{1}$ An AMMA instrument is defined as a sensor or set of sensors allowing for a coherent spatio-temporal sampling of a geophysical variable or of a set of inter-related variables with respect to the study of a given process (for instance, a network of 30 recording raingauges sampling the multi-scale rainfall variability over a mesoscale site is defined as one instrument), see the implementation plan for details (AMMA-ICIG, 2006).
} 
Table I. Summary of the EOP deployment (2005-2007).

\begin{tabular}{|c|c|c|c|}
\hline $\begin{array}{l}\text { Atmosphere dynamics } \\
\text { ( } 9 \text { instruments; } 22 \text { sites) }\end{array}$ & $\begin{array}{l}\text { Aerosols and atmospheric } \\
\text { chemistry ( } 6 \text { instruments; } \\
7 \text { sites; } 20 \text { sensors) }\end{array}$ & $\begin{array}{l}\text { Ocean ( } 2 \text { cruises per } \\
\text { year }=6 \text { instruments) }\end{array}$ & $\begin{array}{l}\text { Hydrology and vegetation } \\
\text { (25 instruments; } \\
\text { I70 sites; > } 300 \text { sensors) }\end{array}$ \\
\hline $\begin{array}{l}\mathbf{3} \text { RS arrays, } \mathbf{2} \text { I stations } \\
\text { covering the whole region }\end{array}$ & $\begin{array}{l}\text { Dust Aerosol Transect, } \\
\mathbf{3} \text { stations: TEOM, Lidar } \\
\text { andphotometer* }\end{array}$ & $\begin{array}{l}\text { I Ship (+2 in 2006), six } \\
\text { cruises in total (see map) }\end{array}$ & $\begin{array}{l}3 \text { groups of } 2 \text { water vapour } \\
\text { and } \mathrm{CO}_{2} \text { stations: } 6 \text { sites }\end{array}$ \\
\hline $\begin{array}{l}2 \text { GPS arrays, } \mathbf{6} \text { stations, } \\
\text { measuring the total } \\
\text { atmospheric water content }\end{array}$ & Aerosol deposits (Lamto) & $\begin{array}{l}34 \text { surface drifters and } \\
45 \text { Argo profilers }\end{array}$ & $\begin{array}{l}3 \text { groups of } 2 \text { sensible heat } \\
\text { flux stations }+1: 7 \text { sites }\end{array}$ \\
\hline I VHF radar (Djougou) & $\begin{array}{l}\text { PBL Nox, Djougou } \\
\text { PBL Nox, Hombori }\end{array}$ & $\begin{array}{l}322 \text { CTD profiles } \\
670 \text { expendable } \\
\text { bathythermographs } \\
\text { (XBT) deployed }\end{array}$ & $\begin{array}{l}\text { IR scintillometer, Djougou } \\
\mathbf{3} \text { raingauge networks }\end{array}$ \\
\hline I X-band radar (Djougou) & $\begin{array}{l}\mathrm{CO}_{2} \text { Balloon (Hombori) } \\
\text { Weekly ozone RS, } \\
\text { Cotonou }\end{array}$ & & $\begin{array}{l}2 \text { spectro disdrometers } \\
3 \text { surf waterrecording } \\
\text { networks }\end{array}$ \\
\hline $\begin{array}{l}2 \text { UHF radars (Bamako, } \\
\text { Ouagadougou) }\end{array}$ & & 25 I RS over the ocean & $\begin{array}{l}3 \text { piezo networks, } \\
\text { aquifers } \\
3 \text { soil moisture: } 8 \text { sites in } \\
\text { total } \\
3 \text { vegetation } \\
\text { monitornetworks }\end{array}$ \\
\hline
\end{tabular}

Instruments in bold had an operating rate of more than $80 \%$; instruments in normal text: 50-80\%; instruments in italic: less than $50 \%$. See localisation in Figure I. Note that the IDAF (chemistry) and PHOTON (optical depth) stations in Figure I are LOP instruments and are thus not listed here. All the EOP hydrology and vegetation measurements were concentrated over the three mesoscale sites represented as hatched areas in Figure I.

* Measuring optical depth particle size distribution, solar radiation absorption.

hundred sensors installed in about 200 different sites spread over a dozen countries. Embedded in this longterm period, was the EOP (2005-2007), which saw the implementation of specific land-based and sea-based instruments. At the core of the EOP a 1-year series of SOPs was organized in 2006, during which intensive measurements from the ground (continent-based and ocean-based) and from the air (research aircraft and balloons) took place (47 additional ground-based instruments, six aircrafts, three ships, PBL, upper atmosphere and stratospheric balloons).

The AMMA field programme was unique in many respects. First of all, the programme was conceived with intensive campaigns embedded in a 9-year longterm monitoring, covering a 3 million $\mathrm{km}^{2}$ area. Second, this huge observational effort was carried out in a region where operational networks were failing, and the European project provided support to retool entirely a 23-station sounding network (Parker et al., 2008; Fink et al., 2011). From 2006 to 2008 and beyond, 21 of these 23 stations operated, making West Africa a much more 'visible' region on the Global Telecommunication System than ever before; it is undoubtedly very rare for a research programme to yield such a large upgrade of an operational network. Third, the EOP and SOP campaigns were - to our knowledge - the first with coordinated air-land-ocean surveys at a regional scale, including all the Tropical Atlantic, most of the West African subcontinent and the atmosphere from the local boundary layer to the stratosphere.

The AMMA deployment is shown in Figure 1. More detailed maps may be found in Lebel et al. (2009) for the LOP on the continent and in Lebel et al. (2010) detailing the SOP ground deployment and aircraft missions. Table I below summarizes the EOP deployment and provides some explanations to Figure 1.

The AMMA - phase 1 legacy goes beyond the scientific advances made, thanks to the field programme. At the time of writing (early 2010), a number of AMMA observing systems are still operating and several of them are funded for the next 4 years.

\section{Accomplishments}

\section{I. Scientific results}

Many important results have already been obtained from the AMMA field measurements. While some of these results are described in this $A S L$ special issue, it is especially worth noting that six other special issues ${ }^{2}$

${ }^{2}$ Six special issues are devoted to presenting AMMA results in various fields:

1. AMMA-SOP0 Special Issue. Journal of Geophysical Research, 2008, 113, D00C17, DOI:10.1029/2008JD010077.

2. AMMA tropospheric chemistry and aerosols. Atmospheric Chemistry and Physics, 2008, 8-9.

3. Surface processes and water cycle in West Africa, studied from the AMMA-CATCH observing system. Journal of Hydrology, 2009, 375(1-2).

4. West African Weather Prediction and Predictability, Weather and Forecasting, 2010, 24.

5. Advances in understanding atmospheric processes over West Africa through the AMMA field campaign, Quarterly Journal of the Royal Meteorological Society, 2010, 136 (S1).

6. West African Monsoon and its Modeling, 2010, Climate Dynamics, 35(1). 
have been produced in the 2 years following the end of the EOP, devoted to particular sub-disciplines. This illustrates the quality, novelty and scientific breadth of the data collected during the AMMA campaigns. The reader is referred to these special issues and to the papers of this special issue (Polcher et al., 2011; for an overview) for grasping the many advances made in various areas (atmospheric dynamics, aerosols and chemistry, oceanic dynamics and their linkage with the WAM system, water cycle and hydrology, impact studies).

From past experiments we know that the AMMA data set will be used for decades to come in order to refine our understanding of the basic geophysical processes involved in the WAM dynamics. More challenging and uncertain is the extent to which these data will contribute to integrative science, whether by helping to address scale issues, or by building bridges between disciplines. A first step in that direction are the ALMIP (AMMA Land Surface Model Intercomparison Project) exercises, in which Land Surface Models will be evaluated using observational data from the three heavily instrumented AMMA mesosites, in order to evaluate the effect of scale change on the representation of the most important processes from the local to the regional scale. This is typically the sort of project which integrates different research communities and which will lead to evaluating the value of the AMMA observations.

\subsection{Operational successes}

Beyond the scientific wealth of the AMMA data set, it is not a vain assertion to state that AMMA is the most successful observational programme into environment and climate ever conducted in Africa, from an operational point of view. This can be quantified by levels of funding, instrument deployment, success rate in term of collected data, and levels of publication using those data. ${ }^{1}$

1. Funding. The success of AMMA was largely conditioned by the possibility for the programme to build on an array of national (France, Germany, UK, USA) and pan-national funds (EU). While the different sources of funding and the different accounting systems in the various participating countries make it difficult to provide a consolidated budget for the whole project, the number of participants in the field (more than 500 in 2006 alone) and of instruments deployed (see below) attest to

A series of AMMA-related papers also appeared in:

1. Journal of Geophysial Research, 2009, 114, focusing on the results of the deployment of the ARM mobile facility in Niamey in 2006 (Radagast experiment).

2. Journal of the Atmospheric Sciences, 2010, 66-67, focusing on the results of the NAMMA component of AMMA (Cyclone genesis over the continental-oceanic transition). an impressive convergence of resources. Obviously this convergence was made possible by the fact that there were some earlier starters giving credit to the idea of a big climate and environmental programme in Africa.

2. Deployment. The success of the instrument deployment (Table I) is all the more notable, given the various logistical problems encountered, running from time and cost needed for transportation, to power supply in remote areas devoid of any electrical network. The aircraft deployment was also a plain success, despite the fact that this was the first scientific mission for the two newly acquired French aircraft. Except for EGEE-5 (in June 2007), shortened by a non-fatal accident, the oceanic cruises by the French, German and US research vessels went on as planned. The AMMA operation centre (AOC) set up for managing the instrument deployment was a key factor of this success. The main AOC was based in Niamey with ancillary centres in Bénin, Burkina Faso and Senegal. One of its main accomplishments was the creation of a communication network to coordinate air, sea and ground operations and the management of communications between the main AOC and the ancillary sites. The main AOC was also successful in setting up a forecasting centre in Niamey, linked to the Météo-France forecasting centre in Toulouse. This operation included the training of a dozen African forecasters that are now using the new forecasting tools created for AMMA to the benefit of the meteorological services of their respective countries. More than 600 hundred scientists and technicians were involved in the AMMA operations in a harsh and often unsecured environment. Despite this, no major casualty was recorded except for a few isolated incidents.

3. Coordination. A specific coordination structure was setup to manage the field campaigns. The International Coordination and Implementation Group (ICIG) was given mandate from the International Scientific Steering committee (ISSC) to produce a global international implementation plan (AMMAICIG, 2006) and to supervise 10 task teams (TTs) in charge of identifying the needs and managing the deployment of instruments of a certain category and four support teams (STs) in charge of gathering the information from the TTs in order to translate them into concrete logistical action. The whole process was not always very smooth, given the number of instruments to deploy and the diversity of situations to handle.

4. Success rate of data collection. There were some delays in the deployment of a few EOP instruments, especially the flux station network (see below). Apart from that, the rate of data delivery by the various LOP, EOP and SOP instruments was quite good (most often above $80 \%$ ) given the conditions of operation. Instruments which produced less than $80 \%$ of foreseen data were usually 
radiosonde stations located in remote areas where telecommunications were poor and the delivery of consumables was difficult (security problems were also a problem in places like Tessalit). A great part of this high success rate is explained by the presence of an important number of skilled people on the instrumented sites.

\section{Lessons for the future}

It is very unlikely that any future programme in climate and environmental research in Sub-Saharan Africa will be similar to AMMA as the scientific objectives, the operational requirements and the funding and institutional context will necessarily be different. However, there are certainly a few lessons to be learnt from AMMA that could be useful for such programmes in the future.

\section{I. The need for early international coordination at the top}

AMMA was very much built as a bottom-up initiative. The main benefit of this was the incredible enthusiasm that allowed the overcoming of financial and operational difficulties. Scientific teams that acted independently at the start of the project were collectively committed to succeeding, and worked together to monitor and fix problems On the other hand, this meant that a large share of the funding was obtained at national levels before the international coordination was established, leading to some inconsistency in the objectives of national programmes. One raison d'etre for AMMA was the scientific integration and therefore observational coordination was paramount, but the inconsistency of national objectives worked against this. Despite the fact that the ICIG was set up in 2005, it had to struggle hard before most teams recognized the benefit of a central field operation coordination. Many contacts were taken on a bilateral basis between European- or US-based scientific teams, and what they thought were their 'natural' African host institution. These initiatives were sometimes mutually inconsistent and could have ended up in serious problems. Setting up the AMMA international governing board (IGB) proved to be a much more difficult and slower process than writing the International Scientific Plan (ISP) and organising the field campaigns (while the ISP was written in 2003 and the first operational plan finalised in early 2005, the first true IGB meeting was held in 2006). Such a discrepancy between the tempo of the scientific community at the bottom and that of the institutions at the top is certainly not specific to AMMA. In our case, a concrete practical consequence of this state of affairs was, however, the difficulty to setup a project office of appropriate size in time. The result was that most of the AMMA logistical management was carried out by scientists who would have been better employed taking care of the scientific strategy and implementation. Optimising the deployment of so many instruments, at different locations and different time periods, is a considerable challenge for the scientists, and there were cases where, for example, the opportunity for the coordination of ground-based and airborne instruments was missed. Setting up an international project office in a rational way and in time would have required us to centralise funds coming from very different sources, and a stronger international framework for AMMA back in 2002 would have helped with this. The lack of strong international coordination also impacted on the capacity building actions whose objectives were not very clearly stated at the onset of AMMA. Communication, which is more and more important in international science, also suffered at the beginning from the absence of a well-structured project office.

\subsection{Coordination and planning for the field deployment}

1. Coordination. Setting up a strong coordination structure for the field deployment is key to success. A community of scientists who used to work in tropical regions does exist and its members are fairly autonomous in deploying their instruments. On the other hand, in a large programme such as AMMA, people are understandably attracted by the scientific challenge of working in an unfamiliar environment for them. Left to their own, the probability that they fail is significant. As the relevance of the whole project depends on a proper deployment of all the instruments, having some of them not deployed or not working will compromise its success. Many scientists do not like to operate in a coordinated way, which is sometimes perceived as unnecessarily bureaucratic, and sometimes the success of their individual work is maximised when they are working in an unconstrained way. An illustration of this are the observations deployed on a few ancillary sites, thanks to funding obtained independently of the AMMA dynamics (e.g. Dano in Burkina Faso and around Dakar). Their location was ideal to complement the latitudinal sampling provided by the AMMA-CATCH mesosites. However, the period and type of deployment was not coordinated by ICIG and in the end these measurements had some local value but their contribution to the integrated studies promoted within AMMA was limited. It is thus important to propose a modus operandi that appeals to participating scientists, and to convince them sufficiently in advance of the value of coordinated work. Ensuring good linkages with the African institutions and scientists is of course a key part of the action of the coordinating structure (see below).

2. Instruments. Instruments with good data delivery rates were those shipped well ahead of the deadline date for starting operation. There are a number of unexpected impediments in transportation, 
customs, research authorizations, local logistics that require a large time 'safety net', between the moment the instrument is sent and the moment it will operate in the field. Furthermore, the first deployment is not always successful because the chosen site is not appropriate; some adjustments are then needed that can include moving the instrument to another location. Also, many instruments are operated in an untested environment, and it is not rare that 1 year of operation is needed before having them working properly. Thus in the planning of such a field programme, it is important to plan well ahead and to start the deployment as soon as possible. Another important point is the working force. Instruments with the lowest data delivery rate were often those who were left unattended (automatic data acquisition and routine sampling protocols theoretically allows this mode of operation), or attended by insufficiently skilled people (young students, or untrained local people).

\subsection{Capacity building, long-term linkages with the African community}

In a document published by the Conference of Parties at the end of the Copenhagen meeting, it is written: 'despite the progress made, only limited advances have been made in achieving longterm continuity for several in situ observing systems and that there are still large areas, in Africa for example, for which in situ observations and measurements are not available'. This statement is in line with the AMMA approach to imbed intensive observation periods of short duration into a longterm observation strategy. In AMMA, we witnessed a beginning of integration between African groups and European groups, thanks to a major investment of effort from some motivated researchers. AMMA-Africa is now a network registering more than 200 names of African scientists. About 50 of these scientists are still participating actively in longterm observations (AMMA-CATCH, IDAF, PHOTONS, PIRATA observing systems), or in modelling activities, as testified by the authorship of the papers of the special issues listed in Section 3.1. As of today, 28 young African students gained a PhD as a result of work on AMMA, while 51 more are currently engaged in a $\mathrm{PhD}$. Ten conferences, summer schools and workshops were organised by AMMA-Africa between 2005 and 2010 (see http://www.aird.fr/ripiecsa/formation.htm). Securing this effort for the future will not be possible unless key regional organisations, able to mobilise funds, are involved. African scientists working in African institutions are not well paid and they often need to work outside the scientific community to make a living. Thus the role of strong regional institutions in drafting a research agenda in climate and environment should be fostered; theses institutions should be given a clear mandate to promote and organise the research at the regional level and to fund directly high-level African scientists so that they can stay in African research institutions and in this way reinforce them.

\section{Acknowledgements}

The support of the AMMA project is gratefully acknowledged (see http://onlinelibrary.wiley.com/doi/10.1002/asl.331/full for full acknowledgement).

\section{References}

AMMA-ICIG. 2006. The international implementation plan of AMMA, version 3 http://amma-international.org/library/docs/IIP_v3.0.pdf, 3 volumes.

Fink A, Agustí-Panareda A, Parker DJ, Lafore J-P, Ngamini JB, Afiesimama E, Beljaars A, Bock O, Christoph M, Didé F, Faccani C, Fourrié N, Karbou F, Polcher J, Mumba Z, Nuret M, Pohle S, Rabier F, Tompkins AM, Wilson G. 2011. Operational meteorology: observational networks, weather analysis and forecasting. Atmospheric Science Letters 12: 135-141, DOI: 10.1002/asl.324.

Lebel T, Cappelaere B, Vieux B, Galle S, Hanan N, Kergoat L, Levis S. 2009. Surface processes and water cycle in West Africa, studied from the AMMA-CATCH observing system. Journal of Hydrology 375(1-2): 3-13.

Lebel T, Parker DJ, Flamant C, Bourles B, Marticorena M, Mougin E, Peugeot C, Diedhiou A, Haywood JM, Ngamini JB, Polcher J, Redelsperger J-L, Thorncroft CD. 2010. The AMMA field campaigns: multiscale and multidisciplinary observations in the West African region. Quarterly Journal of the Royal Meteorological Society 136(S1): 8-33.

Parker DJ, Fink A, Janicot S, Ngamini J-B, Douglas M, Afiesimama E, Agusti-Panareda A, Beljaars A, Dide F, Diedhiou A, Lebel T, Polcher J, Redelsperger J-L, Thorncroft C, Wilson G. 2008. The AMMA radiosonde program and its implications for the future of atmospheric monitoring over Africa. Bulletin of the American Meteorological Society 89: 1015-1027.

Polcher J, Parker DJ, Gaye A, Diedhiou A, Eymard L, Fierli F, Genesio L, Höller H, Janicot S, Lafore J-P, Karambiri H, Lebel T, Redelsperger J-L, Reeves CE, Ruti P, Sandholt I, Thorncroft C. 2011. AMMA's contribution to the evolution of prediction and decision-making systems for West Africa. Atmospheric Science Letters 12: 2-6, DOI: 10.1002/asl.320.

Redelsperger J-L, Thorncroft C, Diedhiou A, Lebel T, Parker D, Polcher J. 2006. African Monsoon, Multidisciplinary Analysis (AMMA): an international research project and field campaign. Bulletin of the American Meteorological Society 87: 1739-1746. 